\title{
Introduction: Back to the Things Themselves! (again)
}

\author{
Astrida Neimanis and D. R. Koukal
}

What is neither here nor there, now nor then? What resides or occurs in the in-between, and what is its meaning, purpose, potential, or effect? And what of the edges that mark the liminality of both this in-between, and the phenomena on either side of it? Can the in-between be known, can we dwell there-or do we only ever traverse this phenomenon, pass through or pass over? Do edges draw a clear line in the proverbial sand, or do they rather shift like the waves of sands across a desert? How do the phenomena of the in-between and edges support one another, challenge one another, or even form the condition of possibility for one another?

These were some of the questions that we posed to our potential collaborators in our call for contributions to this Special Topics edition of PhaenEx. The responses collected here, we hope, will both challenge and provoke you not only to rethink the ways in which various edges and in-betweens structure and condition our lived experience, but also to reimagine the ways in which practical and collaborative phenomenological practices might offer both inspired and inspiring means of exploring these questions. Hence the objective of this collection was twofold: in the first place, it sought to learn something about these related phenomena, the inbetween and edges. However, in order to desediment our preexisting understandings of these phenomena, a second and concomitant objective was called for, that is, an explicit request (as we phrased it in our calls for papers) "to temporarily liberate ourselves from textual exegesis, and 
return to the lived world to divine the essential structures of experience through rigorous phenomenological description." And indeed, if truth be told, in key ways this second objective preceded the first, for the earliest inklings of what would eventually become this collection could be glimpsed at EPTC/TCEP's annual meeting at the University of Western Ontario in May 2005, when your two co-editors began a series of conversations that essentially asked one principal question: How might we cultivate a forum for our colleagues not only to write about phenomenology, but to do phenomenology, in a rigorous and sustained way? In direct response to this question, we convened two "Back to the Things Themselves!" (BTTTT!) events at EPTC/TCEP's annual meetings in 2007 and 2008, which featured a cumulative total of thirteen papers and two workshops that showcased various phenomenological approaches to diverse manifestations of edges and the in-between.

But we certainly were not the first two scholars to ask this question. In fact, our efforts to foster the practice of phenomenology over the past two years can be directly traced back to Herbert Spiegelberg, who conducted a series of phenomenological workshops at Washington University in St. Louis between 1965 and 1972; in 1975 he published Doing Phenomenology, the first half of which lays out a comprehensive program for collaborative phenomenology, in an attempt to raise group philosophizing to the dignity of "a method of cooperative research" (Spiegelberg 24; also see Grant 561). One attendee of these St. Louis meetings was the facilitator of our 2008 workshop and contributor to this volume, Ed Casey, who in the mid-1990s presented a paper on Spiegelberg's workshop approach to the inaugural meeting of "To the Things Themselves," a small conference centered on generating phenomenological descriptions organized by Anthony Steinbock at the University of New Hampshire. In the next phase of this history (as earlier documented by another contributor to the present volume, Stuart Grant), these 
conferences followed Steinbock to Southern Illinois University in Carbondale (Grant, 563), which were attended by yet another contributor to this volume, Glen Mazis (who was good enough to facilitate our 2007 workshop). At the same time, these Carbondale meetings caught the attention of a number of graduate students at Duquesne University. A few attended these meetings, who returned to Pittsburgh to enthusiastically report the novelty of attending to the things themselves. One of your co-editors of this collection was at Duquesne at the time, and though he never attended any of the Carbondale meetings, he was inspired by these reports. Commencing in 2001, he started generating and presenting small phenomenological sketches, first at the Society for Phenomenology and Media, and later at EPTC/TCEP, which was where he met your other co-editor, and the above-mentioned conversations began to shape what eventually became BTTTT!

Spiegelberg's workshops may be a touchstone for the practice of phenomenology (at least in North America), but it is important to remember that Husserl first called for the "resolute cooperation among a generation of research-workers" in phenomenology in the Logical Investigations, a call that he reiterated regularly throughout his published work. ${ }^{1}$ Husserl thought collaboration among researchers to be essential to phenomenology, because it allows a depth of investigation beyond the capabilities of any single subject or any single generation of subjects. In Husserl's view, each practicing phenomenologist is necessarily limited by the finitude of his or her own particular perspective. This "private" perspective is only an instance of subjective experience as such, and as such it must be set aside in order to practice phenomenology with rigor. In describing their lived experience to one another, phenomenologists working as coordinated researchers strive to eliminate, refine clarity, and test observations through comparisons. In other words, description is the means of pulling each practicing 
phenomenologist out of their particular subjectivity. The collaborative phenomenologist must be willing to look and look again from different angles and perspectives, first from afar and then closer, focusing on persistent obscurities and carefully correcting earlier observations, elaborating and clarifying until the eidos emerges to fuse particulars into meaningful wholes.

We take seriously this idea of phenomenological collaboration, as a way of exploring different individual approaches to doing phenomenology, as a way of collectively clarifying phenomenological insights regarding specific fields of phenomena, and as a way of advancing the various practices of phenomenology as a whole. While during our own convened panels on "Edges and the In-Between," this collaboration was limited to the thoughtful ten-minute responses offered by commentators and the always-lively twenty-minute discussions that followed each individual author's paper, we hope that our introduction of the "collaborative workshop" into EPTC/TCEP's conference format extended the possibility for us to dialogue with colleagues and collectively explore some of the questions raised in the individual papers, and those around the practice of phenomenology itself. This experimentation will continue in our third annual BTTTT! panel and workshop to be held at EPTC/TCEP's 2009 annual meeting at Carleton University in Ottawa.

But in the meantime, we hope that this collection extends our goal of collaboration in another way. This is a collaboration that has been taken up between our authors and their anonymous reviewers, between our authors and their persistent co-editors, and not least, between our authors and you, their readers. We thus invite you to engage with these various papers in this same spirit of collaboration. We hope you might glean some insight on the in-between and edges from what you read here, but we also hope that thereafter you might take up these insights and 
extend them further, whether explicitly in responses to the authors, or more implicitly, as these threads become entangled in the tapestries of your own projects.

In the contributions that follow, you will find many diverse sightings of edges and the inbetween: Edward Casey's edges of the painterly canvas, Glen Mazis's cyborg in-betweens, Stuart Grant's “abysmal” laughter, Randall Teal's motel-at-the-edge-of-town, Iris Aravot's explorations of architectural making, Astrida Neimanis's daily commutes, and Kevin Love's being startled. But of course, these various phenomenologies extend far beyond the bounds of the concrete objects in which their descriptions are anchored. While each takes up an extended set of questions within its own parameters, at the same time, various conversations and counterpoints begin to circulate between these contributions as well. In-between the contributions by Grant, Mazis, and Teal, for example, you may notice common attention to what the in-between might teach us about our essential humanity, and how in embracing certain in-between experiences we might even learn to become more human. You might discern a certain "productive tension" that continues to emerge at the edges and in-between, for example, in Casey's musings on the creativity that happens at the edge of the brain, or in Neimanis's location of a similar creativity that pops up from and out of the in-betweens of a body in motion; Aravot, too, uncovers the creative tension that emerges from the in-between space of what is known and what is expected, should the architect be brave enough to let go of their edges and dive into this abyss. You may also note a common consideration of the delicacy required to contact the in-between in the first place, as Mazis, Aravot and Neimanis all remark on the certain "letting be" or "letting go" that is needed in order to allow creativity to emerge in the in-between, as the lessons or gifts of this often ephemeral and transient zone cannot be willed too forcefully. Finally, you will also note that phenomenological methods and practices are not only tools for the writing of the papers 
collected here, but are themselves phenomena whose edges and in-betweens are explored in various ways. Aravot, for example, looks at the relation between phenomenology and architectural making both as practices that require a delving into the abyss of the in-between, while Grant uses his phenomenology of laughter in part to further his on-going interest in phenomenology not only as philosophical method but as a pedagogical tool as well. Neimanis, meanwhile, finds methodological fecundity in the in-between of Merleau-Ponty's embodied phenomenology and the rhizomatics of Deleuze and Guattari, thus edging phenomenology towards (and perhaps over) its own edges. But it is Love's contribution that most explicitly takes up the question of phenomenology's own edges, in its interrogation of the startle-a phenomenon, Love argues, that implores us to reconsider some of phenomenology's own principal tenets and methodological grounds. And, in his Afterword that closes this collection, Koukal returns us again to the question of phenomenological practice, as he dares us scholars to continue to describe the world with which we are intertwined.

In this collection you will thus find in-betweens and edges both spatial and temporal, both ontological and epistemological, both human and more-than-human, both "strange" and "familiar" (to borrow from the title of Teal's paper). Movement becomes entangled in dwelling; being is perforated with becomings; that which marks an end turns out to be only a beginning. Indeed, if one of our objectives in this collection was to map the essential structures or matrices of meaning that imbue both edges and the in-between, then at the very least we have learned that these conjoined phenomena serve to dismantle many of our binaristic categories of lived experience at the same time as they hold such categories in relation. And, while these phenomena are in themselves complex, they also serve as complexifiers and intensifiers of the 
many other lived phenomena that they border, structure and compose. This is an exciting and inspiring tour of edges and the in-between, and we hope it will leave you similarly inspired.

In closing, we would like to thank the many people who lent a hand in the publication of this Special Topics issue. Among these individuals are other members of the PhaenEx Editorial Collective who served as copyeditors, as well as Kim Ligers, Sharon Vlahovich, our managing editor Paul Gyllenhammer and our anonymous reviewers. Special thanks also goes to the editors of Phenomenology \& Practice, who agreed to lend us some of their own anonymous reviewers; we hope this will be the beginning of further fruitful collaboration. We would also like to thank artist Ilga Leimanis for allowing us to use her provocative take on edges and the in-between as the cover image for this issue. Finally, we extend our sincerest thanks to all authors, commentators, workshop facilitators and other participants at EPTC/TCEP's BTTTT! panels and workshops, who have made this project such an enjoyable endeavor, and who have convinced us that it is one worth continuing.

\section{Notes}

${ }^{1}$ Logical Investigations, volume one, 256. Also see "Philosophy as a Rigorous Science," 139, Ideas I, §§ 66-69 and 87, Formal and Transcendental Logic, § 5.

\section{Works Cited}

Grant, Stuart. "Practical Intersubjectivity." Janus Head 8.2 (2005): 560-580.

Husserl, Edmund. "Philosophy as a Rigorous Science." Phenomenology and the Crisis of Philosophy. Trans. Quentin Lauer. New York: Harper \& Row, 1965.

- Formal and Transcendental Logic. Trans. Dorion Cairns. The Hague: Martinus Nijhoff, 1969. 
- viii -

Astrida Neimanis and D. R. Koukal

—. Logical Investigations. Volume One. Trans. J. N. Findlay. London: Routledge and Kegan Paul; New York: Humanities Press, 1970.

- The Crisis of European Sciences and Transcendental Phenomenology. Trans. David Carr. Evanston: Northwestern University Press, 1970.

—. Ideas I. Trans. F. Kersten. Dordrecht, The Netherlands: Kluwer Academic Publishers, 1982.

Spiegelberg, Herbert. Doing Phenomenology: Essays On and In Phenomenology. The Hague: Martinus Nifhoff, 1975. 